\title{
COMPORTAMENTO DO STAPHYLOCOCCUS AUREUS CAUSADORES DE INFECÇÕES HOSPITALARES, FRENTE A ATIVIDADE "IN VITRO” DA FOSFOMICINA
}

\author{
Clara Pechmann Mendonça * \\ Vera Lygia Ferreira Lourenço* \\ Mario Tsunezi Shimizu* \\ Paulo Roberto Natalino* \\ Ivone Shizuko Anno*
}

RSPU-B/242

MENdonçA, C. P. et al. - Comportamento do Staphilococcus aureus causadores de infecçóes hospitalares, frente a atividade "in vitro" da fosfomicina. Rev. Saúde públ., S. Paulo, 9:11-4, 1975

RESUMO: Estudou-se a atividade "in vitro" da fosfomicina em 337 amostras de Staphylococcus aureus coletados de infecções intra-hospitalares, obtendo-se 310 amostras sensiveis $(91,9 \%)$. Comparando-se com outros antimicrobianos, concluiu-se que a atividade da fosfomicina foi superior a todos.

UNITERMos: Staphylococcus aureus. Infecçâo hospitalar. Fosfomicina.

Os primeiros trabalhos científicos sobre o antibiótico fosfomicina apareceram na 9. Conferência Interciência de Agentes Antimicrobianos e Quimioterápicos, em Washington, no ano de 1969.

A fosfomicina obtida inicialmente em caldo de fermentação de Streptomyces fradiae e depois Streptomyces viridicromogenes e wedmorensis ${ }^{6,15}$, sendo facilmente sintetizado ${ }^{2}$. E um antibiótico de amplo espectro, altamente sensível, de boa tolerância e que atua sobre a bactéria inibindo a etapa inicial da biossíntese da parede celular impedindo a formação do ácido $\mathrm{N}$-acetil murâmico ${ }^{13}$.

Pode ser administrado por via oral, intra-muscular e endovenosa. Difunde-se bem em todos os líquidos orgânicos atingindo a barreira liquorica após uma hora da sua presença no sangue. Atravessa a placenta atingindo o líquido amniótico na concentração equivalente ao sangue materno. Difunde-se facilmente na linfa e ossos ${ }^{3}$.

Não foram registradas manifestações tóxicas com o uso desse antibiótico ${ }^{4,5,14}$.

E bastante ativo tanto "in vivo" como "in vitro" extendendo sua ação sobre numerosas bactérias Gram-negativas e principalmente sobre Gram-positivas.

Devido ser eliminado principalmente por via urinária em forma ativa ${ }^{4,5,11}$ é considerado eficaz no tratamento de infecção urinária como provam numerosos trabalhos já apresentados ${ }^{1,3,6,8,12}$.

" Do Departamento de Microbiologia da Faculdade de Farmácia e Odontologia de Araraquara, SP - Rua Expedicionários do Brasil, 1621 - Araraquara, SP - Brasil 
MENDONCA, C.P. et al. - Comportamento do Staphilococcus aureus causadores de infecçōes hospitalares, frente a atividade "in vitro" da fosfomicina. Rev. Saúde públ., S Paulo, $9: 11-4,1975$.

Como se difunde bem em exudato brônquico, apresentando concentrações relativamente altas, tem sido usado com sucesso nos casos de broncopneumopatias ${ }^{9}$.

Nosso trabalho foi realizado com a finalidade de estudar o comportamento do Staphylococcus aureus obtidos de infecçóes hospitalares frente a atividade "in vitro" da fosfomicina, comparando com o de outros antibióticos já testados.

\section{MATERIAL E METODOS}

Os Staphylococcus aureus testados de uma amostra de 337 foram coletados de infecções hospitalares e pertencem a nossa coleção.

Para o teste de sensibilidade a antibióticos foram utilizados os seguintes discos fabricados pela Dfico:

\begin{tabular}{|c|c|c|}
\hline Penicillin G & - & \\
\hline Streptomycin & - & 10 \\
\hline Chloromycetin & - & 30 \\
\hline Tetracycline & - & 30 \\
\hline Ampicillin & - & 10 \\
\hline Methicillin & 一 & \\
\hline Nalidix acid & & \\
\hline
\end{tabular}

$$
\begin{aligned}
& \text { Gentamicin - } 10 \mathrm{mcg} \text {. } \\
& \text { Cephaloridine }-30 \mathrm{mcg} \text {. }
\end{aligned}
$$

Os discos contendo $50 \mathrm{mcg}$. de fosfomicina foram fornecidos por gentileza da Companhia Espanhola de Penicilina e Antibióticos (CEPA).

As placas com meio de Agar Müeller Hinton receberam inóculo de 18-20 horas em Tripticase Soy Broth diluído a 1:1000. Após secagem em estufa a $37^{\circ} \mathrm{C}$, por 15 min, receberam os discos e foram deixados em temperatura ambiente por mais de 30 min para pré-difusão e só depois incubados a $37^{\circ} \mathrm{C}$.

Após 18-20 horas foi feita a leitura considerando-se sensivel o halo de inibição de $12 \mathrm{~mm}$ ou mais.

\section{RESULTADOS E DISCUSSAO}

A fosfomicina apresentou mais ativa que os demais antimicrobianos testados, aparecendo com 310 amostras sensíveis $(91,9 \%)$ seguindo-se a Cefaloridine com $293(86,9 \%)$ e a Gentamicina com 222 $(65,8 \%)$ (ver Tabela).

TA B ELA

Resultado da sensibilidade "in vitro" do Staphylococcus aureus obtidos de infecçoes

\begin{tabular}{|c|c|c|c|c|}
\hline \multirow{2}{*}{ Antimicrobianos } & \multicolumn{2}{|c|}{ Sensiveis } & \multicolumn{2}{|c|}{ Resistentes } \\
\hline & n.o & $\%$ & no & $\%$ \\
\hline Penicillin G & 60 & 17,8 & 277 & 82,2 \\
\hline Streptomycin & 28 & 8,3 & 309 & 91,7 \\
\hline Chloromycetin & 139 & 41,2 & 198 & 58,8 \\
\hline Tetracycline & 109 & 32,3 & 228 & 67,7 \\
\hline Ampicillin & 83 & 24,6 & 254 & 75,4 \\
\hline Methicillin & 65 & 19,2 & 272 & 80,8 \\
\hline Nalidix acid & 51 & 15,1 & 286 & 84,9 \\
\hline Gentamicin & 222 & 65,8 & 115 & 34,2 \\
\hline Cephaloridine & 293 & 86,9 & 44 & 13,1 \\
\hline Fosfomicina & 310 & 91,9 & 27 & 8,2 \\
\hline
\end{tabular}
hospitalares frente a 10 antimicrobianos 
MENDONCA, C.P. et al. - Comportamento do Staphilococcus aureus causadores de infecçôes hospitalares, frente a atividade "in vitro" da fosfomicina. Rev. Saude pübl., s. Paulo, 9:11-4, 1975 .

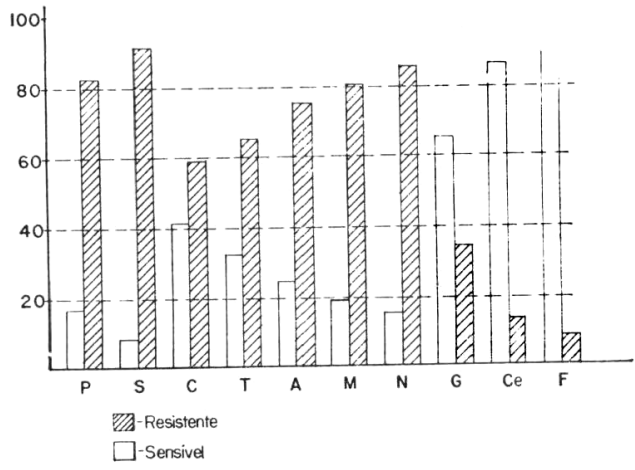

Figura - Sensibilidade e resistēncia ao Staphylococcus aureus a dez agentes antimicrobianos.

Através da Figura podemos verificar em porcentagem todas as sensibilidades e re- sistência dos Staphylococcus aureus frente aos antimicrobianos testados.

Hutzler e col. ${ }^{10}$ em semelhante observação verificaram que a Gentamicina foi sensivel para $93.6 \%$ das amostras seguidas da Fosfomicina com $91.0 \%$ e Cefaloridina com $87.3 \%$.

Fazendo-se uma comparação entre os fagotipos dos Staphylococcus testados e a atividade "in vitro" a fosfomicina, observamos que das 27 amostras resistentes. 23 pertencem ao grupo I de Cowan; 3 ao grupo II e um que não respondeu a fagotipagem a 1 e a 100 RTD. Não possuimos maiores dados para se poder tirar qualquer conclusão.

Mendonça, C. P. et al. - [The behazior of Staphylococcus aureus responsible for hospital infections in the presence of Phosphomycin activity "in vitro".] Rev. Saúde públ., S. Paulo, 9:11-4, 1975.

SUMmary: An "in vitro" study of Phosphomycin acturty envolving $33 y$ samplcs of Staphilococcus aureus collected from hosputal infections was carried out. $310(91.9 \%)$ of these turned ont to be sensitive to the antibiotic. On analysing Phosphomycin the conclusion was that its acturity proved to be superior to that of other antimicrobial agents.

UNITERMS: Staphylococcus aureus. Hospital Infections. Phosphomycin.

\section{REFERENCIAS BIBLIOGRAFICAS}

1. BARNETT, J.A. et al. - Evaluation of MK-955 in urinary tract infection. Antmicrob. Agents Chemother. 1969. p 349-51, 1970.

2. CHRISTEnSEN, B.G. et al, - struture and synthesis of Phosphonomycin. Science, 166:123-5, 1969.

3. CLARK, H. et al - Evaluation of MK955 a new cell wall active antibiotic Antmarob. Agents Chemother. 1969. p. $339-42,1970$.
4. FOLTZ E.L. \& WALLICK. H. - Pharmacodynamics of phosphonomycin (MK-955) following intravenous administration in man. Antimicrob. Agents Chemother. 1969. p. 316-21, 1970 .

5. FOLTZ, E.L. et al. - Pharmacodinamics of phosphonomycin after oral administration in man. Antimicrob. Agents Chemother. 1969. p 322-6, 1970 .

6. GOMES, LLS, R. \& RIOJA. A. apud LA- 
MENDONÇA, C.P. et al. - Comportamento do Staphilococcus aureus causadores de infecçôes hospitalares, frente a atividade "in vitro" da fosfomicina. Rev. Saúde públ., S. Paulo, 9:11-4, 1975 .

GUNERO, L.R. \& MENENDEZ, L. M. ${ }^{12}$.

7. HENDLIN, D. et al. - Phosphonomycin, a new antibiotic produced by strains of Streptomyces. Science, 166:122-3, 1969.

8. HOLLOWAY, W.J. et al. - Preliminary trials with MK-955. Antimicrob. Agents Chemother. 1969. p. 327-31, 1970.

9. HONORATO, F. et al. - Fosfomicina en bronconeumopatías agudas. Rev. Med. Univ. Navarra, 27:1-10, 1973.

10. HUTZLER, R.U. et al, - Atividade "in vitro" da fosfomicina em relação a germes causadores de infeccões hospitalares. Rev. bras. Med., 31:433-6, 1974.

11. KESTLE, D.G. \& KIRBY, W.M.M. Clinical pharmacology and in vitro - activity of MK-955, a new antibiotic. Antimicrob. Agents Chemother., 1969. p. 332-7, 1970.
12. LAGUNERO, L.R. \& MENENDEZ, L.M. - Infecciones urinárias tratadas con fosfomicina. Folia clin. int., BarceIona, $2: 1-15,1974$.

13. LORENZO-VELASQUES, B. - Un nuevo antibiotico, sencillo, de amplio espectro y de buena tolerancia. La fosiomicina. Arch. Fac. Med., Madrid, 23:307-10, 1973.

14. MILlER, A.K. et al. - Phosphomycin. Evaluation in mice. Antimicrob. Agents Chemother. 1969. p. 310-5, 1970.

15. STAPLEY, E.O. et al. - Phosphonomicin. Discovery and in vitro blological characterization. Antimicrob. Agents Chemother. 1969. p. 284-90, 1970.

Recebido para publicaৎão em 13-11-74

Aprovado para publicasão em 13-01-75 